\title{
Electronic chromo-endoscopy: technical details and a clinical perspective
}

\author{
Partha Pal, Aniruddha Pratap Singh, Navya D. Kanuri, Rupa Banerjee \\ Department of Medical Gastroenterology, AIG hospitals, Hyderabad, India \\ Contributions: (I) Conception and design: R Banerjee, P Pal, AP Singh; (II) Administrative support: R Banerjee; (III) Provision of study materials or \\ patients: R Banerjee; (IV) Collection and assembly of data: R Banerjee, P Pal, AP Singh; (V) Data analysis and interpretation: P Pal, AP Singh; (VI) \\ Manuscript writing: All authors; (VII) Final approval of manuscript: All authors. \\ Correspondence to: Dr. Rupa Banerjee, Sr. Consultant Gastroenterologist. Department of Medical Gastroenterology, AIG hospitals, Plot No 2/3/4/5, \\ Survey No 136, 1, Mindspace Rd, Gachibowli, Hyderabad, Telangana 500032, Hyderabad, India. Email: dr_rupa_banerjee@hotmail.com.
}

\begin{abstract}
Precise endoscopic assessment is necessary to detect neoplastic changes in an early stage. Electronic or virtual chromo-endoscopy (ECE) is an alternative to conventional dye-based chromoendoscopy which markedly improves capillary pattern and hence can detect micro-vessel morphological changes of early neoplasia to target biopsies and aid in diagnosis. The clinical significance increased after the advent of endoscopic treatment modalities like ESD/EMR which requires precise delineation of extent and depth of lesion. Most of the studies have used narrow-band imaging (NBI) (Olympus Medical Systems Tokyo, Japan), although data from i-SCAN (PENTAX Endoscopy, Tokyo, Japan) and flexible spectral imaging color enhancement (FICE) (Fujinon, Fujifilm Medical Co, Saitama, Japan) are emerging. Electronic chromo-endoscopy is convenient compared to dye-based chromo-endoscopy in the sense that it is available at the push of a button in endoscope and reduces procedure time substantially with comparable efficacy. Scope of this review is to discuss available electronic chromo-endoscopy modalities and their role in the diagnosis, surveillance, and management of early GI neoplasia.
\end{abstract}

Keywords: Electronic chromoendoscopy; narrow-band imaging (NBI); I-SCAN; flexible spectral imaging color enhancement (FICE); Blue laser imaging (BLI); Linked colour imaging (LCI)

Received: 21 December 2019; Accepted: 12 May 2020; Published: 25 January 2022.

doi: $10.21037 /$ tgh-19-373

View this article at: http://dx.doi.org/10.21037/tgh-19-373

\section{Introduction}

White light endoscopy was an important milestone in gastroenterology enabling not only detection of lesion, assessment of length, extent and severity but also allowing biopsy and endoscopic management of diseases. However standard white light endoscopy (WLI) may miss the subtle lesions of superficial neoplasia specially the early cancer lesions which are usually flat and may appear isochromatic to surrounding mucosa on WLI (1).

Dye based chromo-endoscopy was the first step towards image enhancement. This involved endoscopy with spraying of various dyes on the mucosa in order to facilitate visualization of benign versus cancerous mucosal changes. Several staining agents broadly categorized as absorptive (vital) stains, contrast stains, and reactive stains were used. Absorptive stains (e.g., Lugol's iodine solution and methylene blue) diffuse or are preferentially absorbed by specific epithelial cell membranes; contrast stains (e.g., indigo carmine) highlight surface topography and mucosal irregularities by permeating mucosal crevices \& reactive stains (e.g., Congo red and phenol red) undergo chemical reactions with specific cellular constituents, resulting in a color change. This improved the contrast and was a useful adjunct to routine WLI (2).

Dye based Chromo-endoscopy has been widely used for various indications throughout the gastrointestinal tract (Table 1). However, the technique is often operator dependent and requires additional procedure time including 
Table 1 Electronic chromoendoscopy and clinical applications

\begin{tabular}{|c|c|}
\hline $\begin{array}{l}\text { Scope of electronic } \\
\text { chromoendoscopy }\end{array}$ & Clinical applications \\
\hline \multirow[t]{3}{*}{ Oesophagus } & $\begin{array}{l}\text { Barrett's oesophagus (Figure 1A,1B) and } \\
\text { Barrett associated CA }\end{array}$ \\
\hline & Minimal change oesophagitis (Figure 1C) \\
\hline & Early oesophageal carcinoma (Figure $1 D-1 F$ ) \\
\hline \multirow[t]{4}{*}{ Stomach } & Intestinal metaplasia (Figure 2) \\
\hline & Helicobacter pylori infection \\
\hline & Early gastric cancer (diagnosis) \\
\hline & Gastric polyps \\
\hline \multirow[t]{3}{*}{ Duodenum } & Celiac disease \\
\hline & Ampullary dysplasia or duodenal carcinoma \\
\hline & Familial adenomatous polyposis \\
\hline Small intestine & Angiodysplasia \\
\hline \multirow[t]{2}{*}{ Biliary tract } & Early detection of cholangiocarcinoma \\
\hline & $\begin{array}{l}\text { Differentiation between benign \& malignant } \\
\text { biliary strictures }\end{array}$ \\
\hline \multirow[t]{2}{*}{ Colorectum } & $\begin{array}{l}\text { Detection \& characterization of colonic } \\
\text { polyps }\end{array}$ \\
\hline & $\begin{array}{l}\text { Inflammatory bowel disease (IBD): } \\
\text { dysplasia detection, mucosal healing }\end{array}$ \\
\hline
\end{tabular}

technical expertise in preparing and using the dye (3). The standardization on contrast dilution, dilution methods, concentration and the depth of the color hue, remains unclear. It requires additional instruments like the spray catheter and the dye may not spread evenly across the mucosal surface.

Additionally, switching between white light view and chromo-endoscopic view is not possible. The vascular microstructure is often difficult to assess after spraying dye and can be distorted by the use of dyes like acetic acid which causes vascular congestion. Methylene blue can precipitate met-hemoglobinemia in patients with Glucose6-Phosphatase dehydrogenase deficiency (4). Moreover, the risks of aspiration pneumonitis particularly in sedated elderly patients limits its usage.

Cost effectiveness of dye spray chromo-endoscopy in clinical practice has not been established especially with the advent of high definition endoscopes (5). There is also concern regarding accelerated carcinogenesis with the use of methylene blue due to photo activation in Barrett's oesophagus (BE) screening (6).
Digital chromo-endoscopy in the form of narrow band imaging (NBI), Fuji intelligent chromo-endoscopy (FICE) and can overcome most of these limitations and is now preferred in clinical practice particularly for the early detection of cancers.

\section{Definition of electronic chromoendoscopy}

Electronic chromo-endoscopy or digital chromoendoscopy refers to advanced endoscopic imaging technologies that provide detailed contrast enhancement of the mucosal surface and blood vessels based on the principle of observing light transmittance at selected wavelength given interaction of particular tissue structures with light is wavelength dependent. The advantages of electronic chromo-endoscopy are ease of use, short learning curve, no need of special assembly or dye and shorter procedure time (7).

\section{Electronic chromoendoscopy: technical details}

ECE uses the principle of selective light transmittance. This is achieved by either optical filtering of white light (Narrow Band Imaging) or software driven post image processing (FICE, I-scan). These are hardware based first generation image enhanced endoscopy (IEE) systems. The major drawbacks of these systems are low resolution and dark images at distant view. This is overcome by blue laser imaging (BLI), which was released by Fujifilm corporation in 2013. BLI provides bright images at distant view which can improve colorectal polyp detection rate (8). Further improvement in image enhancement is achieved by novel techniques such as linked colour imaging (LCI) developed by Fujifilm corporation (Tokyo, Japan) (9).

\section{NBI}

NBI is an endoscopic optical image enhancement technology developed by Olympus Medical Systems. It's based on the penetration properties of the light which is directly proportional to the wavelength (10). NBI filter in front of the xenon arch lamp produces 2 narrow bands centered at 415 and $540 \mathrm{~nm}$. These 2 wavelengths correspond to the primary and secondary light absorption peaks of hemoglobin, respectively (11). Capillaries in the superficial mucosa are highlighted by the 415-nm wavelength and appear brown. The longer 540-nm penetrates more deeply and make the deeper veins appear blue-green (cyan) thus creating contrast with the 

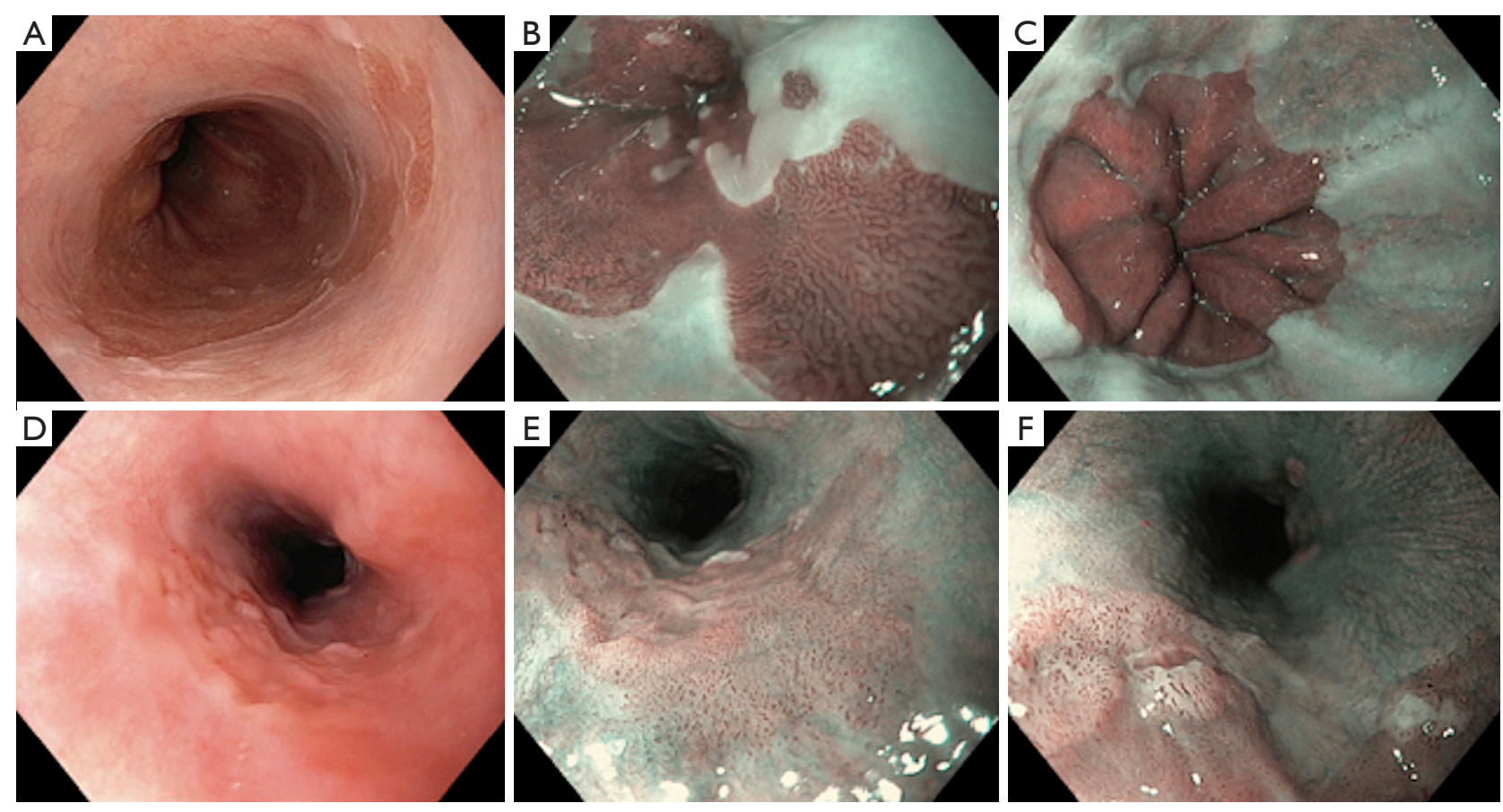

Figure 1 Role of narrow band imaging (NBI) in esophagus (Barrett's oesophagus, minimal change esophagitis and early oesophageal cancer). (A) Barrett's esophagus on white light imaging (WLI); (B) Barrett oesophagus on NBI: regular ridged pit pattern with normal micro-vasculature with no evidence of dysplasia; (C) minimal change esophagitis: dilated intra-papillary capillary loop pattern (IPCLs) type II. These are enlarged but arranged in a linear regular fashion; (D) early oesophageal cancer on WLI: mild nodularity on careful inspection; (E) early oesophageal cancer: NBI image, Brownish discoloration with irregular dilated IPCLs; (F) early oesophageal cancer: NBI with magnification showing small ulcerated area with Type IV IPCLs.
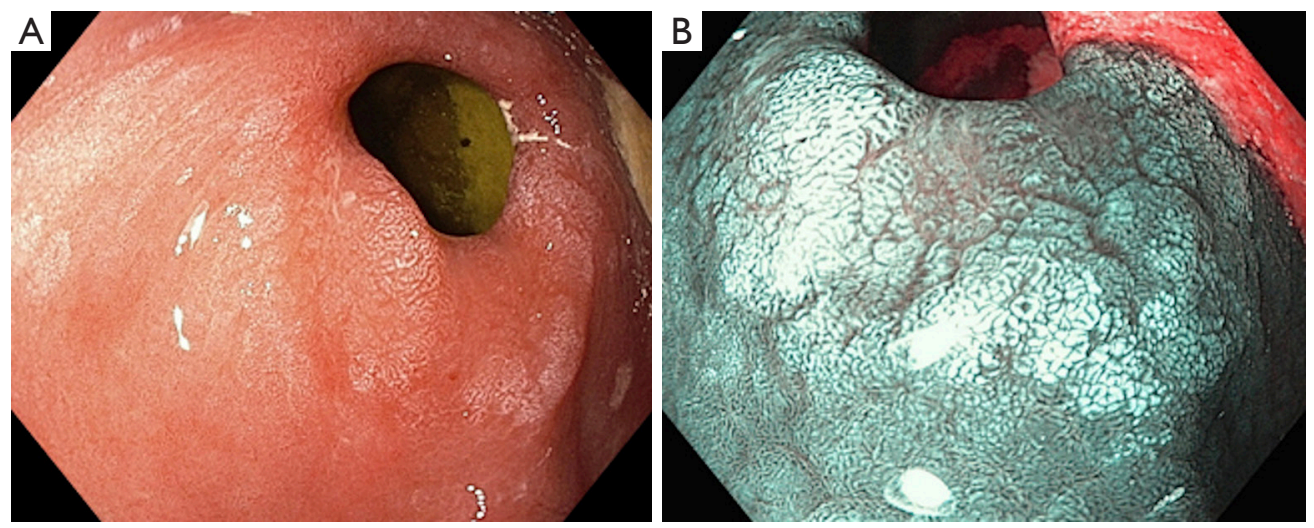

Figure 2 Gastric intestinal metaplasia. (A) White light imaging and (B) narrow band imaging.

nonvascular structures in the mucosa (Figure 3) $(12,13)$.

Currently available video processors and light sources are next generation Evis Exera III released in 2012 which produces brighter image compared to initial commercially available NBI systems such as Evis Exera II 180 system (color CCD system) and the Evis Lucera 260 spectrum series (RGB sequential system). Second generation NBI systems have corrected the issue of darker image in earlier generation by improvements in the light source, system's lenses and mirrors. These modifications have increased 


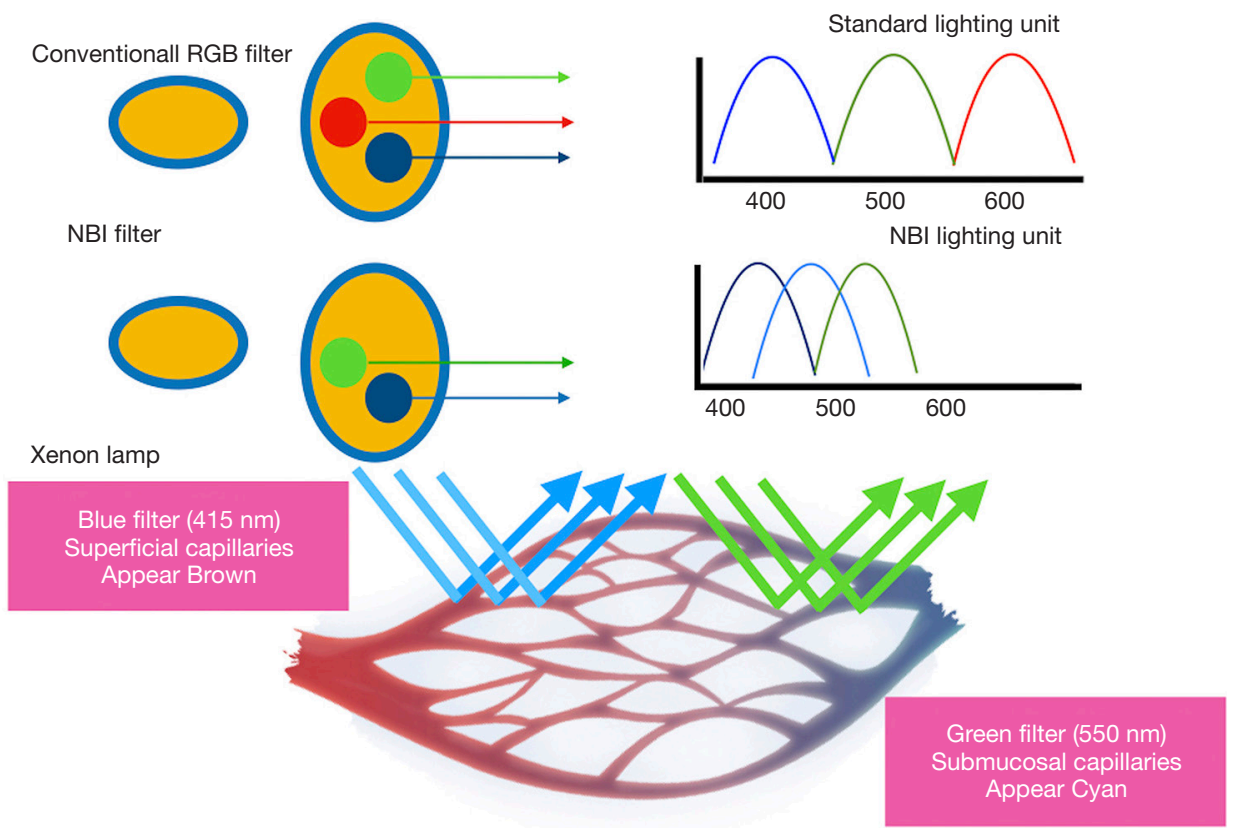

Figure 3 Principles of narrow band imaging.

the brightness of the image by minimising lamp light permeating from the glass fibre within the endoscope and $3 \mathrm{D}$ noise reduction capability (12).

\section{FICE}

FICE is a proprietary digital post-processing system of Fujinon (13). FICE is based on a Spectral Estimation Technology invented by Professor Yoichi Miyake from Tokyo. The Captured image is sent to the Spectral Estimation Matrix processing circuit in the EPX-4400 where various pixilated spectrums of the image are estimated. Since the spectrums by pixels are known, it is possible to implement imaging on a single wavelength. Such single wavelength images are randomly selected, and assigned to $\mathrm{R}$ (Red,) $\mathrm{G}$ (Green,) and B (Blue) respectively to build and display a F.I.C.E. enhanced color image $(8,13)$.

Ten factory-determined presets are available. Each preset can be button activated from the computer keyboard and can be changed manually to possible permutations of the available wavelengths (from 400-695 nm) that can be manipulated in 5-nm increments. The endoscopy push button can be programmed to enable switching between the conventional white-light image and up to 3 FICE presets. However, the major limitation of the FICE system is that the optimal settings have not been clearly established (13).

\section{i-SCAN}

i-SCAN is a digital, post processing image enhancement technology from PENTAX Endoscopy similar to FICE that provides digital contrast to endoscopic images. There are 3 i-SCAN modes $-1 / 2 / 3$. They comprise of surface enhancement (SE-enhanced mucosal surface texture), Contrast enhancement (CE-sharpened views of surface vessels), Tone enhancement (TE-increases the contrast between the mucosa and blood vessels improving visibility of blood vessels) and Tone enhancement mode $g$ (improves visualisation of grimly lit far-field regions) which functions by performing per pixel modifications of the white light image. i-SCAN 1 has CE and SE mode. i-SCAN 2 has CE, $\mathrm{SE}$ and TE mode whereas i-SCAN 3 has CE, SE, TE $\mathrm{g}$ mode (Table 2). i-SCAN 3 differs from i-SCAN 2 primarily in its ability to illuminate more distant regions better. Unlike NBI, red remains the predominant blood vessel color in all i-SCAN modes. Switch from WLE to i-SCAN occurs almost instantly. PENTAX processors with i-SCAN capability are EPK-i5010 with LH-150PC as the light source $(8,14)$.

\section{BLI}

BLI uses monochromatic lasers (410 and $450 \mathrm{~nm}$ ) in place of xenon light (NBI). The $410 \mathrm{~nm}$ laser acts like NBI with shorter wavelength which highlights the micro-vasculature 
Table 2 Different I -SCAN modes and their functions

\begin{tabular}{lll}
\hline Mode & Enhancement & Functionality \\
\hline i-SCAN (Modes off) & SE/CE/TE -off & High definition white light endoscopy \\
i-SCAN 1 & SE/TE & Sharpens surface vessels and enhances surface texture of mucosa \\
i-SCAN 2 & SE, CE, TEC & Increases contrast between mucosa and blood vessels, enhances surface texture of mucosa \\
i-SCAN 3 & SE, CE, TEg & $\begin{array}{l}\text { Increases contrast between mucosa and blood vessel including dimly illuminated far-field regions, } \\
\text { enhances surface texture of mucosa }\end{array}$ \\
\hline
\end{tabular}

whereas $450 \mathrm{~nm}$ laser acts by exciting phosphors to create white light which provides white light illumination. Ratio of the intensity of the two lasers can be changed to provide a illumination for both normal and narrow band observation. Furthermore, brighter images can be derived by using optical filters $(15,16)$.

BLI has 3 modes: (I) BLI mode- for detailed magnified observation; (II) BLI bright mode- both vascular and surface pattern analysis even from distant view; (III) white light mode- uses laser $(450 \mathrm{~nm})$ rather than conventional white light which better enhances the micro-vasculature. Most colorectal polyps can be diagnosed with good accuracy by BLI magnification. Hiroshima classification can be used to delineate polyps by BLI as it uses both surface and vascular pattern. According to this classification, A depicts non-adenomatous polyps, B depicts adenomatous polyps, C1 depicts intra-mucosal carcinoma, C2 depicts slight submucosal invasion $(<1,000 \mu \mathrm{m})$ and $\mathrm{C} 3$ depicts deep submucosal invasion $(>1,000 \mu \mathrm{m})$. According to a study BLI was accurate for all the subtypes except for C2 which requires conventional chromo-endoscopy with pit pattern analysis for better characterisation $(15,16)$. Blue Light Imaging using LED light source (Eluxeo system) that is now available in Europe, US and Asia/Australia. The original BLI using Laser light (LASEREO) is commercially available in Japan and Asia-Pacific (17).

\section{LCI}

LCI is a novel IEE technique which increases image contrast. Although novel modalities like BLI produces brighter images, it is still criticized for dark image contributing to low diagnostic rate. BLI uses green and blue light for red colour adjustment like NBI. Hence LCI has been introduced. It uses information of all three colours for signal processing. LCI differentiates the red colour spectrum more effectively than WLI. The increased colour contrast improves detection of inflammation and results in more accurate delineation. By unique image processing, it makes red regions more vivid and white region clear white (9).

There is substantial evidence to suggest roe of LCI in detecting early gastrointestinal neoplasms by enhancing color contrast between neoplasm and surrounding mucosa (18). This distinction is made by specific color allocation based mainly on the distribution of capillaries. It helps in early detection of pale and superficial neoplasms providing sufficient brightness to illuminate wide lumen by novel image processing which is a distinct advantage over NBI and BLI. Early gastric cancers and intestinal metaplasia appear orange-red and purple on LCI respectively (19). In colon, LCI improves the adenoma detection rate and decreases the polyp miss rate (20).

\section{Role of NBI in BE}

NBI sharpens the visual fields while inspecting squamocolumnar junction and can help detect Barrett's and dysplasia (Figure $1 A, 1 B$ ). Various studies have compared HD-WLE with HD-NBI for detection of Barrett's and associated dysplasia $(21,22)$. A Randomized crossover study by Kara et al. showed that HD-WLE and HD-NBI are comparable in detecting high grade dysplasia (HGD) with a sensitivity of $79 \%$ and $86 \%$ respectively (21). But a multicenter, randomised study by Sharma et al. compared the two and have found that NBI-HD significantly detects more number of HGD $(30 \%$ vs. $21 \%, \mathrm{P}=0.01)$ and require less number of biopsies $(3.6 \%$ vs. $7.3 \%, \mathrm{P}<0.0001)$ compared to HD-WLE (22). In a meta-analysis, sensitivity, and specificity of HD-NBI in diagnosing, HGD is $96 \%$ and $94 \%$ respectively and, specialized intestinal metaplasia (SIM) is $95 \%$ and $65 \%$ respectively (23). This is supported by other studies and meta-analysis showed better detection of oesophageal dysplasia and cancer with NBI compared to WLE (24). There are also studies on reproducibility of NBI findings. However, the results showed moderate inter observer agreement and that the inter-observer agreement 
was not improved by NBI over HD-WLE (25).

Using NBI, different classifications have been proposed. Classifications used for BE with magnification narrow band imaging or electronic chromo-endoscopy are listed (Table 3) (25-28).

\section{Role of I-SCAN in BE}

The role of I-SCAN in detecting dysplasia in Barrett's esophagus is evolving with influx of new data. I-SCAN post processing endoscopic imaging has been shown to be superior to white-light endoscopy in the detection of intestinal metaplasia in BE in previous studies $(29,30)$. In a recent study by Lipman et al., addition of acetic acid and Magnification imaging (PENTAX EG 2990 Zi magniview endoscope) to I-SCAN significantly increased the accuracy of the I-SCAN classification system $(69 \%$ to $79 \%, \mathrm{P}=0.01)$. $\mathrm{BE}$ associated dysplasia detection rate was significantly improved compared to HD-WLE and I-SCAN alone ( $83 \%$ vs. $76 \% ; \mathrm{P}=0.047$ ). Inter-observer agreement of the classification system was moderate, although it improved to substantial when incorporated into a clinical decisionmaking protocol $(\kappa=0.69)$. Small subgroup analysis of LGD lesions showed a comparable accuracy of $80 \%$ (28). In spite of that, it did not meet the ASGE PIVI threshold for adopting this instead of current practice of random biopsies given limitations of small sample size, low prevalence of dysplasia in examined cohort and use of videos rather than still images (30,31).

A further modification of the iSCAN system by optical enhancement (OE) uses both pre and post processing images which can improve dysplasia detection rate without the addition of ACA, thus reducing procedure time (32). as shown in study by Everson et al., which also showed that prediction of histology was better with iSCAN OE compared to HD-WLE by both expert and trainee endoscopists (33).

\section{Role of FICE in BE}

There is very limited data on the use of FICE in BE, A small pilot study including 18 patients with acetic acid application, HGD was identified in $100 \%$ patients as compared to 14\% using HD-WLE (34). FICE channel 4 images were significantly better than the conventional images (35). In a study consisting of 40 patients comparing FICE and WLE, visualization of palisade vessels and demarcation of $\mathrm{BE}$ and gastric mucosa was better made by FICE compared to
WLE (36). Pohl et al. compared chromoendoscopy with acetic acid application (CAA) with FICE for detection of HGD in BE in a randomised cross over trial and found that sensitivity of both the modalities were similar (87\%) and found out sensitivity at around $87 \%$. Sensitivity of directed biopsies for detection of neoplasia was $83 \%$ and $92 \%$ for CAA and FICE respectively, although the difference was not statistically significant (37).

\section{Electronic chromo-endoscopy in esophageal squamous cell carcinoma (ESCC)}

Electronic chromoendoscopy has enabled early detection of ESCC by predicting of depth and extent of the lesion, as submucosal invasion increases probability of lymph node metastasis. Esophageal stratified squamous epithelium is featureless with no pit pattern and regular palisading capillary network (Figure 1D,1E). Esophageal microvascular structure including intrapapillary capillary loop pattern (IPCL) can be visualized with clarity using NBI. IPCL is a smooth running small diameter $(10 \mu \mathrm{m})$ capillary vessel positioned upright from a branching vessel. Branching vessels appear green while the IPCLs are observed as dark brown loops/dots on NBI. Minimal mucosal changes are easily missed by WLE because of flat and isochromatic appearance of superficial ESCC (38). Chai et al. demonstrated usefulness of HD-NBI compared to HDWLE in detecting ESCC (adenoma detection rate 70.2\% vs. $35.7 \%$ respectively, $\mathrm{P}<0.01)$. Most of the missed lesions were high grade intraepithelial lesions (39). In a recent systematic review and meta-analysis including 1,911 patients by Morita et al., NBI fared better than conventional chromoendoscopy with Lugol's iodine to diagnose high grade intraepithelial neoplasia and ESCC (40).

Most widely used ME-NBI classification is by Inoue $e t$ al. (Figure 4) but due to its complexity it's not widely popular among the endoscopists (41).

A simplified NBI with magnifying endoscopy (NBI-ME) criteria (dyad criteria) by Dobashi et al. defined the lesion endoscopically as superficial ESCC based on 6 NBI-ME findings: inter-vascular background coloration, proliferation of IPCLs, dilatation/tortuosity/change in calibre/various shapes of IPCL (42). It was validated in a prospective comparative trial of 170 patients at high risk of ESCC, 77 were detected to have superficial ESCC with better sensitivity, by DF-NBI than WLI (91\% vs. $51 \%, \mathrm{P}<0.001)$ with high inter (0.77)/intra (0.82) observer agreement (43).

JES (Japanese Esophageal Society) has developed 
Table 3 NBI Endoscopy-Barrett's oesophagus classification systems

\begin{tabular}{|c|c|c|c|c|}
\hline $\begin{array}{l}\text { Morphological } \\
\text { classifications and } \\
\text { their performance }\end{array}$ & Kansas (25) & Nottingham (26) & Amsterdam (27) & $\begin{array}{l}\text { Barrett's International NBI } \\
\text { group (BING) (28) }\end{array}$ \\
\hline \multirow[t]{2}{*}{ 1) Normal } & $\begin{array}{l}\text { Mucosal pattern (MP): } \\
\text { circular }\end{array}$ & \multicolumn{2}{|c|}{$\begin{array}{l}\text { Type A: round/oval pits with MP: regular } \\
\text { regular microvasculature }\end{array}$} & $\begin{array}{l}\text { MP: circular, ridged/villous, or } \\
\text { tubular }\end{array}$ \\
\hline & & & $\begin{array}{l}\text { Abnormal blood vessels } \\
\text { (ABV): absent }\end{array}$ & \\
\hline \multirow{2}{*}{$\begin{array}{l}\text { 2) Intestinal } \\
\text { metaplasia }\end{array}$} & VP: normal & $\begin{array}{l}\text { Type C: absent pits with } \\
\text { regular MW }\end{array}$ & VP-regular (villous/gyrus) & \\
\hline & & & ABV: absent & \\
\hline \multirow[t]{2}{*}{ 3) Dysplasia } & MP: irregular/distorted & $\begin{array}{l}\text { Type D: distorted pits with } \\
\text { irregular MW }\end{array}$ & MP-irregular & $\begin{array}{l}\text { MP: absent or irregular } \\
\text { patterns }\end{array}$ \\
\hline & VP: abnormal & & VP: irregular & $\begin{array}{l}\text { VP: focally or diffusely } \\
\text { distributed vessels not } \\
\text { following normal architecture } \\
\text { of the mucosa }\end{array}$ \\
\hline \multirow{4}{*}{$\begin{array}{l}\text { Performance } \\
\text { of various } \\
\text { classifications }\end{array}$} & $\begin{array}{l}\text { The sensitivity, specificity, } \\
\text { and PPV of irregular/ } \\
\text { distorted pattern for HGD } \\
\text { were } 100 \%, 98.7 \% \text {, and } \\
95.3 \% \text {, respectively }\end{array}$ & $\begin{array}{l}\text { PPV \& negative predictive } \\
\text { value (NPV) for type A } \\
\text { (Columnar mucosa without } \\
\text { IM) was } 100 \% \& 97 \% \\
\text { respectively }\end{array}$ & $\begin{array}{l}\text { No data on observer } \\
\text { agreement }\end{array}$ & $\begin{array}{l}\text { predictions by the experts } \\
\text { yielded high accuracy }\end{array}$ \\
\hline & & $\begin{array}{l}\text { For Type B \& C (IM) was } \\
88 \% \text { and } 91 \% \text { respectively }\end{array}$ & & $\begin{array}{l}\text { sensitivity, and specificity } \\
(92 \%, 91 \% \text {, and } 93 \% \\
\text { respectively) }\end{array}$ \\
\hline & & $\begin{array}{l}\text { For Type D (high grade } \\
\text { dysplasia) was } 81 \& 99 \%\end{array}$ & & $\begin{array}{l}\text { Inter-observer agreement was } \\
\text { substantial }(\mathrm{k}=0.681)\end{array}$ \\
\hline & & $\begin{array}{l}\text { Inter and Intraobserver } \\
\text { agreement was Kappa of } \\
0.71-0.87 \text { (Nonexperts) and } \\
0.78-0.91 \text { (Experts) }\end{array}$ & & \\
\hline
\end{tabular}




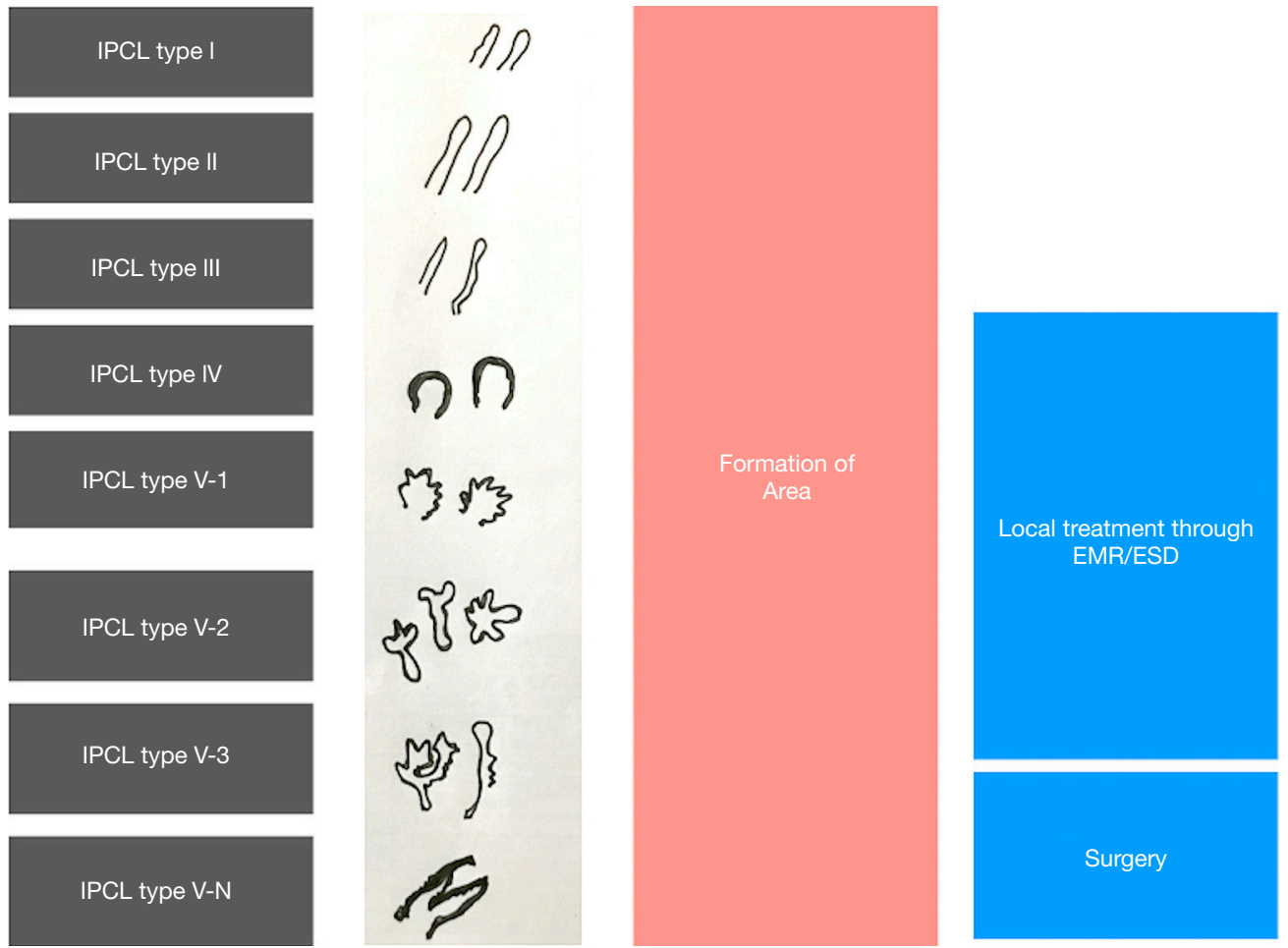

Figure 4 Original intra-papillary capillary loop pattern (IPCL) classification. Adopted from Inoue et al. (37).

Table 4 Modified from Oyama et al.—criteria of the Japanese Endoscopic Society (JES) magnifying endoscopic classification (44)

\begin{tabular}{|c|c|c|c|c|}
\hline Type of vessels & Scheme & Definitions & Invasion depth & Histology \\
\hline B1 & & $\begin{array}{l}\text { Abnormal micro vessels with severe } \\
\text { irregularity or dilated abnormal }(20 \mu \mathrm{m}) \\
\text { vessels, Type B vessels with loop like } \\
\text { formation }\end{array}$ & $\begin{array}{l}\text { T1a-Epithelium, T1a- } \\
\text { Lamina propria mucosa }\end{array}$ & $\begin{array}{l}\text { High grade intraepithelial } \\
\text { neoplasm or invasive squamous } \\
\text { cell carcinoma }\end{array}$ \\
\hline B2 & & $\begin{array}{l}\text { Type B vessels with out a loop like } \\
\text { formation }\end{array}$ & $\begin{array}{l}\text { T1a-MM (muscularis } \\
\text { mucous) or T1b-SM1 } \\
\text { (submucosa) }\end{array}$ & \\
\hline B3 & & $\begin{array}{l}\text { Highly dilated blood vessels }(60 \mu \mathrm{m}) \\
\text { with calibers }>3 \text { times B2 vessels }\end{array}$ & T1b-SM2 or deeper & \\
\hline
\end{tabular}

a simplified magnifying endoscopic classification for estimating invasion depth of superficial esophageal squamous cell carcinomas (Table 4) (44). Overall accuracy of type B1, B2, B3 microvessels to diagnose invasion is $90.5 \%$ which is fairly good.

Standardization of the ME-NBI reports is necessary to develop consensus among the endoscopists. NBI should be used routinely for surveillance and diagnosis of superficial ESCC. FICE can be complementary to lugol chromoendoscopy and magnifying endoscopy for detecting ESCC due to better observation of IPCLs compared to conventional chromoendoscopy. I-scan usage in the management of squamous cell carcinoma of the oesophagus is scarce, routine use cannot be recommended at present. 
Table 5 Gastric lesions classification with narrow band imaging (40)

\begin{tabular}{lllll}
\hline Morphology and diagnosis & A & B & Hp+ (H-pylori infection) & C \\
\hline Mucosal pattern & Regular circular & $\begin{array}{l}\text { Regular ridge/tubulovillous/ Regular } \\
\text { Light blue crest* }\end{array}$ & $\begin{array}{l}\text { Irregular or absent white } \\
\text { opaque substance on the } \\
\text { surface* }\end{array}$ \\
Vascular pattern & $\begin{array}{l}\text { Regular thin/peripheral } \\
\text { (gastric body) or thick/ } \\
\text { central (gastric antrum) } \\
\text { vessels }\end{array}$ & Regular & Regular with variable & Irregular \\
& vormal & vascular density. & & \\
Diagnosis & Intestinal metaplasia & H pylori infection & Dysplasia
\end{tabular}

*, "Light blue crest", defined as fine, blue line on the crest of the epithelial surfaces or gyri, being highly specific for the diagnosis of intestinal metaplasia; **, "White opaque substance" above the mucosa can be associated with dysplasia and cancer.

\section{Electronic chromo-endoscopy in Stomach- Gastric Intestinal Metaplasia, dysplasia, and early gastric cancer}

Electronic chromo-endoscopy has its primary utility in diagnosing early gastric cancer and certain premalignant conditions (e.g., gastric intestinal metaplasia) (Figure 2, Table 5) (45). Most of the studies to date are using NBI systems.

This simplified NBI classification diagnoses gastric intestinal metaplasia with $83 \%$ accuracy for normal histology (pattern A), 84\% for intestinal metaplasia (pattern B) and 95\% for dysplasia (pattern C) with high reproducibility. More than $90 \%$ of the individuals at risk for gastric adenocarcinoma could be identified by application of this simplified classification by better detection of gastric intra-epithelial metaplasia (GIM) (46). Endoscopic grading with score $>5$ for Intestinal metaplasia is identified as optimal cutoff for extensive metaplasia during surveillance but validation studies are lacking (47).

MESDA-C (Magnifying endoscopy simple diagnostic algorithm for early gastric cancer-EGC), has shown its utility in the diagnosis for the evaluation of a suspicious gastric lesion. In a suspicious lesion, the presence of a demarcation line with irregular microvascular/microsurface pattern diagnosed EGC with 97\% accuracy (48).

\section{Miscellaneous applications of electronic chromo-endoscopy}

NBI can also show increased number, dilatation and tortuosity of IPCL's and greater presence of microerosions compared to controls in patients with GERD (49). i-SCAN also showed improved diagnosis of GERD compared to WLE (50).
Villous atrophy associated with celiac disease can be diagnosed with FICE with $100 \%$ accuracy and with NBI with sensitivity of $93 \%$ and $98 \%$ specificity (51). i-SCAN was also useful in complete atrophy (52). Role of NBI in FAP for duodenal adenoma and also to delineate ampullary dysplasia has also been described $(53,54)$.

\section{Electronic chromo-endoscopy in colonic polyps}

Narrow band imaging has been studied most extensively in the management of the colonic polyps, but literature regarding other modalities like I-SCAN and FICE is also evolving.

A consensus-based classification NICE (NBI international colorectal endoscopic classification systems) based on color, vessels, and the surface pattern criteria for endoscopic diagnosis of small colorectal polyps has been developed (Figure 5, Table 6) $(55,56)$.

Microvessel network and thickness of the vessel are ways of assessing histological grade and depth of invasion of colorectal tumors. On real time colonoscopy, endoscopists confidently made diagnosis in $75 \%$ of consecutive small colorectal polyps using NICE classification with high accuracy, sensitivity, and positive predictive values (PPV) (55). In a multicentric prospective study by Puig et al., analysis of more than 2000 colonic lesions $>10 \mathrm{~mm}$, NICE classification identified lesions with deep invasion with $95 \%$ accuracy even by non-experts (57).

Japan Narrow-Band Imaging Expert Team (JNET) classification based on NBI-ME imaging divides NICE type 2 into type 2A (low grade adenomas) and type 2B (high grade adenomas/submucosally invasive cancer) (58). Retrospective analysis of over 2,900 colorectal lesions concluded that JNET classification very reliably predicts histology, except for 

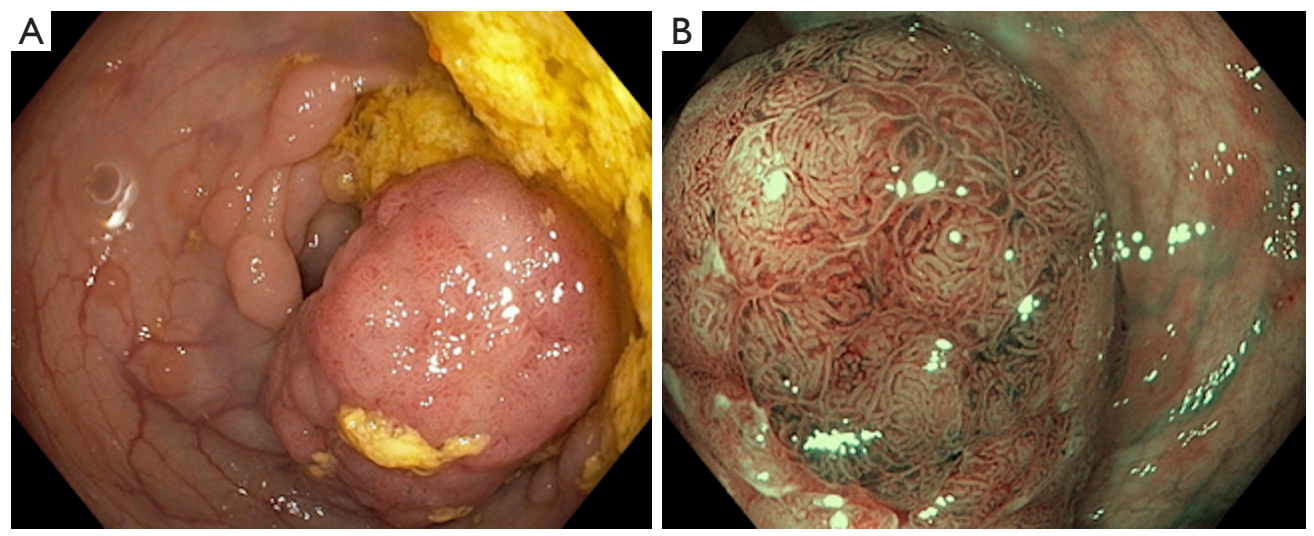

Figure 5 Adenomatous colonic polyp. (A) White light imaging, (B) narrow band imaging.

Table 6 NBI International Colorectal Endoscopic (NICE) Classification $(50,51)$

\begin{tabular}{|c|c|c|c|}
\hline & Type 1 & Type 2 & Type 3 \\
\hline Vessels & $\begin{array}{l}\text { None, or isolated lacy vessels } \\
\text { coursing across the lesion }\end{array}$ & $\begin{array}{l}\text { Brown vessels surrounding white } \\
\text { structures }\end{array}$ & Has areas of disrupted or missing vessels \\
\hline $\begin{array}{l}\text { Surface } \\
\text { pattern }\end{array}$ & $\begin{array}{l}\text { Dark or white spots of uniform size, or } \\
\text { homogeneous absence of pattern }\end{array}$ & $\begin{array}{l}\text { Oval, tubular or branched white structure } \\
\text { surrounded by brown vessels. }\end{array}$ & Amorphous or absent surface pattern \\
\hline $\begin{array}{l}\text { Most likely } \\
\text { pathology }\end{array}$ & Hyperplastic & Adenoma (Figure 5) & Deep submucosal invasive cancer \\
\hline
\end{tabular}

type $2 \mathrm{~B}$ lesions which is less specific and need additional pit pattern examination using dye-based chromo-endoscopy (59). Although small validation studies have been published, large scale validation is still lacking (60).

The "Workgroup Serrated Polyp and Polyposis" (WASP) classification incorporates premalignant lesions like sessile serrated polyps/adenomas (SSA's) and traditional serrated adenomas (TSA) unlike NICE classification. Based on WASP classification, $\geq 2$ features out of clouded surface, indistinct borders, irregular shape and dark spots inside crypts are diagnostic of sessile serrated polyps optically (61).

NBI might be better than standard-WL colonoscopy and equal to HD-WLE for colorectal polyps (62). HDNBI does not fare well in terms of increased ADR or flat adenomas, nor it improves the miss rates in screening colonoscopy (63). In a meta-analysis, HD-NBI improved detection of flat adenomas nearly two-fold at the cost of increased withdrawal time (64). In an RCT comparing new generation (190-NBI) colonoscopy with HD-WLE showed higher colorectal adenoma/polyp detection rate without difference in adenoma miss rate (65). Further improvements in NBI technology like LUCERA ELITE improved polyp visibility and HD PHL (High definition Pentax Hiline) improve ADR by detecting flat adenomas with higher accuracy $(66,67)$.

In a meta-analysis of 13 studies evaluating comparison of sensitivities of various modalities of IEE, NBI $(60 \%)$ and magnification NBI (80\%) were better than WLE for discriminating SSA/Ps from non-neoplastic lesions where's modalities like FICE had poor sensitivity (47\%) to in comparison with WLE, NBI (89\% vs. $75 \%)$ \& M-NBI $(78 \%$ vs. $63 \%$ ) demonstrated greater sensitivity (68).

A systematic review and meta-analysis by Backes et al. showed that both NBI and magnification chromoendoscopy (MCE) are comparable in efficacy in optical diagnosis of T1 colorectal cancer (CRC) with deep 
submucosal invasion when used in adjunct to gross morphological features (GMF). This can be useful to reduce piece-meal resection for T1 CRC or unnecessary surgical referral for endoscopically resectable lesion (69). Another systematic review by Zhang et al. concluded that M-NBI and MCE had comparable specificities but M-NBI has lower sensitivity in diagnosing deep submucosal CRC (70). ASGE \& ESGE endorses use of advanced endoscopic imaging for evaluation \& management of colorectal lesions.

Accurate optical diagnosis and resection of small adenomas $(<10 \mathrm{~mm})$ during colonoscopy can allow hyperplastic polyps to be left in situ and help determining surveillance intervals without need for tissue diagnosis. The sensitivity of NBI was $83.4 \%$ and hence not currently accurate enough to replace histology in determining surveillance intervals (71).

i-SCAN improves resolution of epithelial mucosal surface and vessels, and hence i-SCAN has better efficacy compared to HD-WLE in histological prediction of diminutive colorectal polyps. I-SCAN is comparable to NBI in predicting histology of diminutive colorectal polyps $(72,73)$. Kidambi et al. in a recent randomized trial of 740 patients comparing i-SCAN 1 with HD-WLE colonoscopy, found $9.4 \%$ improvement in the ADR and $10.3 \%$ improvement in the neoplasia detection rate with the use of i-SCAN 1 which was mainly due to better detection of flat, diminutive, right sided adenomas (74). Hoffman in another study found i-SCAN with HD-colonoscopy found more adenomas and flat lesions as compared to SD-WLE (75). However conflicting results has been seen in few other studies. In a prospective cohort study of 84 patients, i-SCAN failed to show any significant improvements in the histology prediction over HD-WLE (76). It was not clear whether the increased sensitivity of I-SCAN with HD was due to HD or I-SCAN. This was answered in a study by Bowman in a prospective study of 1,936 average risk patients for screening colonoscopies, which compared i-SCAN to HD-WLE to detect adenomas and found out that i-SCAN significantly detected more adenomas (618 vs. $402, \mathrm{P}<0.01)$ and advanced adenomas more than $1 \mathrm{~cm}(79$ vs. $47, \mathrm{P}<0.021)$ as compared to HD-WL colonoscopy (77). HD i-SCAN improved ADR when compared to SD-WL colonoscopy with i-SCAN and it also meets ASGE PIVI standards for optical diagnosis of diminutive polyps but only in expert hands and also needs training. Its performance is similar to standard i-SCAN, NBI and FICE (78).

FICE (Fujinon) usage study of colonic polyps is scarce and comes from 2 prospective randomized multicentric studies comparing it with WLE. In one study of 764 patients, there was no significant difference in ADR in FICE group compared to WLE and targeted indigo carmine spraying but sensitivities were comparable in predicting histology (79). Second large RCT by Aminalai et al. including 1,318 patients showed no advantage of the FICE technique over conventional high resolution endoscopy in terms of ADR (80). Chung et al. in a randomized study enrolled 1,650 subjects with 550 in each arm of NBI, FICE and WL, it showed that compared to WLE, NBI nor FICE did not increase ADR rate in the hand of non-experts (81). In a network meta-analysis by $\mathrm{Li}$ et al., in recent study showed that ADR was better with virtual chromo-endoscopy compared to SD-WLE and HD-WLE (82). In a study by Teixeira et al., FICE capillary classification accurately determined nature of colorectal lesions in $98.3 \%$ with high sensitivity, specificity, positive and negative predictive value (NPV) with high interobserver agreement (83). a prospective series from UK showed that FICE along with indigo carmine application significantly improves in vivo diagnosis of colonic polyps over WLI and can lead to significant cost savings avoiding unwanted biopsies (84).

\section{Electronic chromoendoscopy in ulcerative colitis (Figure 6)}

Chromoendoscopy is recommended standard of care for detecting dysplasia in inflammatory bowel disease (IBD) according to all international guidelines $(85,86)$. Chromoendoscopy had an incremental yield of 6\% $(95 \%$ CI, 1-14\%) for the diagnosis of dysplasia over NBI. NBI allowed better detection of in vivo angiogenesis (marker of colonic inflammation) compared to WLE in IBD patients (87). Study with i-SCAN including 78 consecutive patients showed that subtle vascular and mucosal abnormalities in patients with Mayo endoscopy subscore of 0 or 1 at WLE correlated closely with histological and clinical outcome (88). Randomised parallel group trial including 112 patients showed that there was no difference between NBI and HD-WLE with regard to dysplasia detection (89).

Bisschops et al. showed although chromo-endoscopy (CE) and NBI do not differ significantly for detection of dysplasia UC, given the easy applicability of NBI and longer withdrawal time for CE, NBI could replace CE (90).

Kudo et al. studied microvascular pattern for accurate healing in ulcerative colitis (91). In a randomized noninferiority trial of 270 patients, Iacucci et al. showed that 

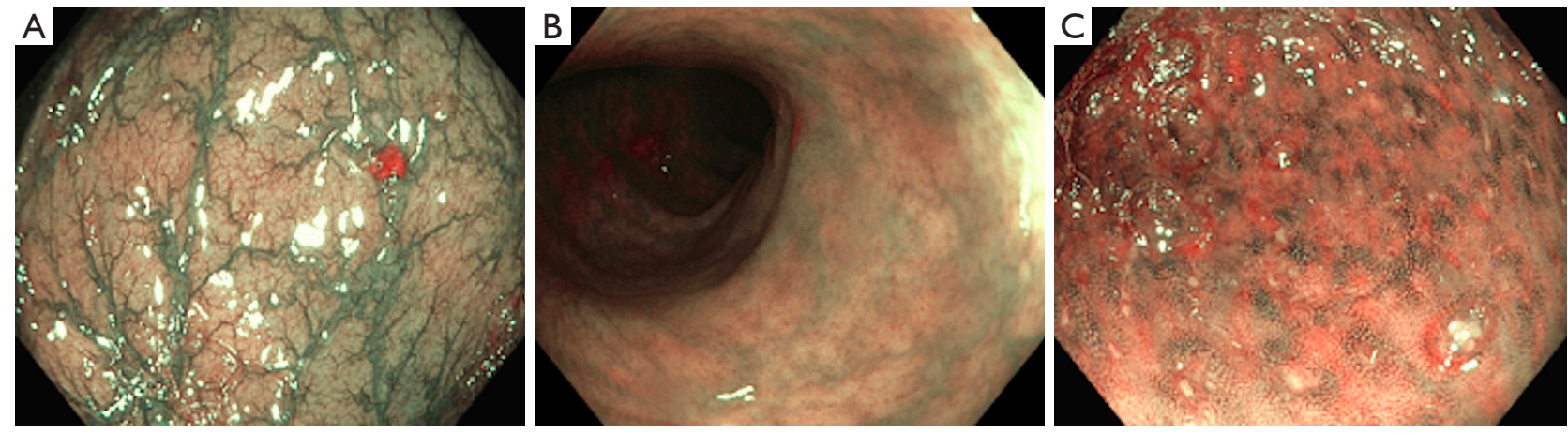

Figure 6 NBI in colorectum. (A) Normal colonic mucosa on NBI; (B) oedematous mucosa with loss of vascular pattern on NBI in UC; (C) UC-active inflammation. NBI, narrow-band imaging; UC, ulcerative colitis.

electronic chromoendoscopy and HD-WLE were noninferior to dye spraying colonoscopy and neoplastic pit pattern (III-V) (OR 21.5) and location within the right colon (OR 6.52) were associated with neoplasia (92). Same group has developed and validated FACILE (Frankfurt Advanced Chromoendoscopic IBD Lesions) which showed that irregular surface, irregular vessel architecture, signs of inflammation and non-polypoidal morphology were the best predictors of dysplastic lesions on histology (93). Using kudo pit pattern, experts differentiated between neoplastic and non-neoplastic lesions with good sensitivity and specificity (94). Use of Kudo pit pattern to predict histology in the presence of inflammation in UC when assessed by standard colonoscopes in non-experts hands is still controversial (95).

Cassinotti et al. in first study of 205 patients using FICE and studying kudo pit pattern in differentiation of the lesions in ulcerative colitis and it accurately identified with sensitivity, specificity, PPV and NPV of $92 \%, 76 \%, 3.8$ and 0.12 respectively. Fibrin cap as a marker of inflammation improves the identification further (96). To conclude electronic chromoendoscopy will be useful in surveillance and management of ulcerative colitis.

\section{Conclusions}

Electronic chromoendoscopy has helped in identifying, delineating and assessing the depth of the lesions in the routine endoscopies at the switch of a button, but validated simple classification systems are the need of the hour to make it more acceptable in clinical practice. NBI is the most popular advanced imaging technique but data regarding FICE, i-SCAN is also emerging. Narrow band imaging has proved to be an useful adjunct in surveillance endoscopies and colonoscopies allowing targeted biopsy with improved detection. Prediction of nature of polyp together with a "Resect and discard" policy for diminutive polyps has become possible but further multicentric studies are needed before we put this into practice.

\section{Acknowledgments}

Funding: None.

\section{Footnote}

Provenance and Peer Review: This article was commissioned by the Guest Editors (Krish Ragunath, Philip WY Chiu) for the series "Advanced Endoscopic Imaging of the GI Tract" published in Translational Gastroenterology and Hepatology. The article has undergone external peer review.

Conflicts of Interest: All authors have completed the ICMJE uniform disclosure form (available at https://tgh.amegroups. com/article/view/10.21037/tgh-19-373/coif). The series "Advanced Endoscopic Imaging of the GI Tract" was commissioned by the editorial office without any funding or sponsorship. The authors have no other conflicts of interest to declare.

Ethical Statement: The authors are accountable for all aspects of the work in ensuring that questions related to the accuracy or integrity of any part of the work are appropriately investigated and resolved.

Open Access Statement: This is an Open Access article 
distributed in accordance with the Creative Commons Attribution-NonCommercial-NoDerivs 4.0 International License (CC BY-NC-ND 4.0), which permits the noncommercial replication and distribution of the article with the strict proviso that no changes or edits are made and the original work is properly cited (including links to both the formal publication through the relevant DOI and the license). See: https://creativecommons.org/licenses/by-nc-nd/4.0/.

\section{References}

1. Kodama M, Kakegawa T. Treatment of superficial cancer of the esophagus: a summary of responses to a questionnaire on superficial cancer of the esophagus in Japan. Surgery 1998;123:432-9.

2. Varadarajulu S, Banerjee S, Barth BA, et al. GI endoscopes. Gastrointest Endosc 2011;74:1-6.e6.

3. Trivedi PJ, Braden B. Indications, stains and techniques in chromoendoscopy. QJM 2013;106:117-31.

4. Konijeti GG, Shrime MG, Ananthakrishnan AN, et al. Cost-effectiveness analysis of chromoendoscopy for colorectal cancer surveillance in patients with ulcerative colitis. Gastrointest Endosc 2014;79:455-65.

5. Olliver JR, Wild CP, Sahay P, et al. Chromoendoscopy with methylene blue and associated DNA damage in Barrett's oesophagus. Lancet 2003;362:373-4.

6. Manfredi MA, Dayyeh BKA, Bhat YM, et al. Electronic chromoendoscopy. Gastrointest Endosc 2015 Feb 1;81:249-61.

7. Osawa H., Yamamoto H. Present and future status of flexible spectral imaging color enhancement and blue laser imaging technology. Dig Endosc 2014;26:105-15.

8. Gono K, Obi T, Yamaguchi M, et al. Appearance of enhanced tissue features in narrow-band endoscopic imaging. J Biomed Opt 2004;9:568-77.

9. Sun X, Dong T, Bi Y, et al. Linked color imaging application for improving the endoscopic diagnosis accuracy: a pilot study. Sci Rep 2016;6:33473.

10. Kuznetsov K, Lambert R, Rey JF. Narrow-Band Imaging: Potential and Limitations. Endoscopy 2006;38:76-81.

11. Thosani N, Abu Dayyeh BK, Sharma P, et al. ASGE Technology Committee, Technology Committee systematic review and meta-analysis assessing the ASGE Preservation and Incorporation of Valuable Endoscopic Innovations thresholds for adopting real-time imagingassisted endoscopic targeted biopsy during endoscopic surveillance of Barrett's esophagus. Gastrointest Endosc 2016;83:684-98.e7.
12. East JE, Vleugels JL, Roelandt P, et al. Advanced endoscopic imaging: European Society of Gastrointestinal Endoscopy (ESGE) Technology Review. Endoscopy 2016;48:1029-45.

13. Miyake Y, Kouzu T, Takeuchi S, et al. Development of new electronic endoscopes using the spectral images of an internal organ. Proceedings of the IS\&T/SID's Thirteen Color Imaging Conference, 2005. Scottsdale, Ariz; 2005:261-9.

14. Kodashima S, Fujishiro M. Novel image-enhanced endoscopy with i-scan technology. World J Gastroenterol 2010;16:1043-9.

15. Togashi K, Nemoto D, Utano K, et al. Blue laser imaging endoscopy system for the early detection and characterization of colorectal lesions: a guide for the endoscopist. Therap Adv Gastroenterol 2016;9:50-6.

16. Nakano A, Hirooka Y, Yamamura T, et al. Comparison of the diagnostic ability of blue laser imaging magnification versus pit pattern analysis for colorectal polyps. Endosc Int Open 2017;5:E224-31.

17. Yoshida N, Dohi O, Inoue K, et al. Blue Laser Imaging, Blue Light Imaging, and Linked Color Imaging for the Detection and Characterization of Colorectal Tumors. Gut Liver 2019;13:140-8.

18. Shinozaki S, Osawa H, Hayashi Y, et al. Linked color imaging for the detection of early gastrointestinal neoplasms. Therap Adv Gastroenterol 2019;12:1756284819885246.

19. Kanzaki H, Takenaka R, Kawahara Y, et al. Linked color imaging (LCI), a novel image-enhanced endoscopy technology, emphasizes the color of early gastric cancer. Endosc Int Open 2017;5:E1005-13.

20. Paggi S, Mogavero G, Amato A, et al. Linked color imaging reduces the miss rate of neo-plastic lesions in the right colon: a randomized tandem colonoscopy study. Endoscopy 2018;50:396-402.

21. Kara MA, Peters FP, Rosmolen WD, et al. Highresolution endoscopy plus chromoendoscopy or narrowband imaging in Barrett's esophagus: a prospective randomized crossover study. Endoscopy 2005;37:929-36.

22. Sharma P, Hawes RH, Bansal A, et al. Standard endoscopy with random biopsies versus narrow band imaging targeted biopsies in Barrett's oesophagus: a prospective, international, randomised controlled trial. Gut 2013;62:15-21.

23. Mannath J, Subramanian V, Hawkey CJ, et al. Narrow band imaging for characterization of high grade dysplasia and specialized intestinal metaplasia in Barrett's esophagus: 
a meta-analysis. Endoscopy 2010;42:351-9.

24. Qumseya BJ, Wang H, Badie N, et al. Advanced imaging technologies increase detection of dysplasia and neoplasia in patients with Barrett's esophagus: a meta-analysis and systematic review. Clin Gastroenterol Hepatol 2013;11:1562-70.e1-2.

25. Kara MA, Ennahachi M, Fockens $P$, et al. Detection and classification of the mucosal and vascular patterns (mucosal morphology) in Barrett's esophagus by using narrow band imaging. Gastrointest Endosc 2006;64:155-66.

26. Sharma P, Bansal A, Mathur S, et al. The utility of a novel narrow band imaging endoscopy system in patients with Barrett's esophagus. Gastrointest Endosc 2006;64:167-75.

27. Singh R, Anagnostopoulos GK, Yao K, et al. Narrowband imaging with magnification in Barrett's esophagus: validation of a simplified grading system of mucosal morphology patterns against histology. Endoscopy 2008;40:457-63.

28. Sharma P, Bergman JJGHM, Goda K, et al. Development and Validation of a Classification System to Identify High-Grade Dysplasia and Esophageal Adenocarcinoma in Barrett's Esophagus Using Narrow-Band Imaging. Gastroenterology 2016;150:591-8.

29. Coletta M, Sami SS, Nachiappan A, et al. Acetic acid chromoendoscopy for the diagnosis of early neoplasia and specialized intestinal metaplasia in Barrett's esophagus: a meta-analysis. Gastrointest Endosc 2016;83:57-67.e1.

30. Sharma P, Savides TJ, Canto MI, et al. The American Society for Gastrointestinal Endoscopy PIVI (Preservation and Incorporation of Valuable Endoscopic Innovations) on imaging in Barrett's Esophagus. Gastrointest Endosc 2012;76:252-4.

31. Lipman G, Bisschops R, Sehgal V, et al. Systematic assessment with I-SCAN magnification endoscopy and acetic acid improves dysplasia detection in patients with Barrett's esophagus. Endoscopy 2017;49:1219-28.

32. Neumann H, Fujishiro M, Wilcox CM, et al. Present and future perspectives of virtual chromoendoscopy with i-scan and optical enhancement technology. Dig Endosc 2014;26:43-51.

33. Everson MA, Lovat LB, Graham DG, et al. Virtual chromoendoscopy by using optical enhancement improves the detection of Barrett's esophagus-associated neoplasia. Gastrointest Endosc 2019;89:247-56.e4.

34. Camus M, Coriat R, Leblanc S, et al. Helpfulness of the combination of acetic acid and FICE in the detection of Barrett's epithelium and Barrett's associated neoplasias. World J Gastroenterol 2012;18:1921-5.
35. Coriat R, Chryssostalis A, Zeitoun JD, et al. Computed virtual chromoendoscopy system (FICE): a new tool for upper endoscopy? Gastroenterol Clin Biol 2008;32:363-9.

36. Osawa H, Yamamoto H, Yamada N, et al. Diagnosis of endoscopic Barrett's esophagus by transnasal flexible spectral imaging color enhancement. J Gastroenterol 2009;44:1125-32.

37. Pohl J, May A, Rabenstein T, et al. Computed virtual chromoendoscopy: a new tool for enhancing tissue surface structures. Endoscopy 2007;39:80-3.

38. Muto M, Minashi K, Yano T, et al. Early Detection of Superficial Squamous Cell Carcinoma in the Head and Neck Region and Esophagus by Narrow Band Imaging: A Multi-center Randomized Controlled Trial. J Clin Oncol 2010;28:1566-72.

39. Chai TH, Jin XF, Li SH, et al. A tandem trial of HD-NBI versus HD-WL to compare neoplasia miss rates in esophageal squamous cell carcinoma. Hepatogastroenterology 2014;61:120-4.

40. Morita FHA, Bernardo WM, Ide E, et al. Narrow band imaging versus lugol chromoendoscopy to diagnose squamous cell carcinoma of the esophagus: a systematic review and meta-analysis. BMC Cancer 2017;17:54.

41. Inoue $H$, Kaga M, Ikeda $H$, et al. Magnification endoscopy in esophageal squamous cell carcinoma: a review of the intrapapillary capillary loop classification. Ann Gastroenterol 2015;28:41-8.

42. Dobashi A, Goda K, Yoshimura N, et al. Simplified criteria for diagnosing superficial esophageal squamous neoplasms using Narrow Band Imaging magnifying endoscopy. World J Gastroenterol 2016;22:9196-204.

43. Dobashi A, Goda K, Furuhashi H, et al. Diagnostic efficacy of dual-focus endoscopy with narrow-band imaging using simplified dyad criteria for superficial esophageal squamous cell carcinoma. J Gastroenterol 2019;54:501-10.

44. Oyama T, Inoue H, Arima M, et al. Prediction of the invasion depth of superficial squamous cell carcinoma based on microvessel morphology: magnifying endoscopic classification of the Japan Esophageal Society. Esophagus 2017;14:105-12.

45. Pimentel-Nunes P, Dinis-Ribeiro M, Soares JB, et al. A multicenter validation of an endoscopic classification with narrow band imaging for gastric precancerous and cancerous lesions. Endoscopy 2012;44:236-46.

46. Boeriu A, Boeriu C, Drasovean S, et al. Narrow-band imaging with magnifying endoscopy for the evaluation of gastrointestinal lesions. World J Gastrointest Endosc 
2015;7:110-20.

47. Lage J, Pimentel-Nunes P, Figueiredo PC, et al. Light$\mathrm{NBI}$ to identify high-risk phenotypes for gastric adenocarcinoma: do we still need biopsies? Scand J Gastroenterol 2016;51:501-6.

48. Muto M, Yao K, Kaise M, et al. Magnifying endoscopy simple diagnostic algorithm for early gastric cancer (MESDA-G). Dig Endosc 2016;28:379-93.

49. Sharma P, Wani S, Bansal A, et al. A feasibility trial of narrow band imaging endoscopy in patients with gastroesophageal reflux disease. Gastroenterology 2007;133:454-64; quiz 674.

50. Kang HS, Hong SN, Ko SY, et al. The efficacy of i-SCAN for detecting reflux esophagitis: a prospective randomized controlled trial. Dis Esophagus 2013;26:204-11.

51. Ianiro G, Gasbarrini A, Cammarota G. Endoscopic tools for the diagnosis and evaluation of celiac disease. World J Gastroenterol 2013;19:8562-70.

52. Cammarota G, Ianiro G, Sparano L, et al. Image-enhanced endoscopy with I-scan technology for the evaluation of duodenal villous patterns. Dig Dis Sci 2013;58:1287-92.

53. Lopez-Ceron M, van den Broek FJC, Mathus-Vliegen EM, et al. The role of high-resolution endoscopy and narrow-band imaging in the evaluation of upper GI neoplasia in familial adenomatous polyposis. Gastrointest Endosc 2013;77:542-50.

54. Uchiyama Y, Imazu H, Kakutani H, et al. New approach to diagnosing ampullary tumors by magnifying endoscopy combined with a narrow-band imaging system. J Gastroenterol 2006;41:483-90.

55. Hayashi N, Tanaka S, Hewett DG, et al. Endoscopic prediction of deep submucosal invasive carcinoma: validation of the Narrow-Band Imaging International Colorectal Endoscopic (NICE) classification. Gastrointest Endosc 2013;78:625-32.

56. Hewett DG, Kaltenbach T, Sano Y, et al. Validation of a simple classification system for endoscopic diagnosis of small colorectal polyps using narrow-band imaging. Gastroenterology 2012;143:599-607.e1.

57. Puig I, López-Cerón M, Arnau A, et al. Accuracy of the Narrow-Band Imaging International Colorectal Endoscopic Classification System in Identification of Deep Invasion in Colorectal Polyps. Gastroenterology 2019;156:75-87.

58. Sano Y, Tanaka S, Kudo S, et al. Narrow-band imaging (NBI) magnifying endoscopic classification of colorectal tumors proposed by the Japan NBI Expert Team. Dig Endosc 2016;28:526-33.
59. Sumimoto K, Tanaka S, Shigita K, et al. Clinical impact and characteristics of the narrow-band imaging magnifying endoscopic classification of colorectal tumors proposed by the Japan NBI Expert Team. Gastrointest Endosc 2017;85:816-21

60. Minoda Y, Ogino H, Chinen T, et al. Objective validity of the Japan Narrow-Band Imaging Expert Team classification system for the differential diagnosis of colorectal polyps. Dig Endosc 2019;31:544-51.

61. IJspeert JE, Bastiaansen BA, van Leerdam ME, et al. Development and validation of the WASP classification system for optical diagnosis of adenomas, hyperplastic polyps and sessile serrated adenomas/polyps. Gut 2016;65:963-70.

62. Nagorni A, Bjelakovic G, Petrovic B. Narrow band imaging versus conventional white light colonoscopy for the detection of colorectal polyps. Cochrane Database Syst Rev 2012;1:CD008361.

63. Pasha SF, Leighton JA, Das A, et al. Comparison of the yield and miss rate of narrow band imaging and white light endoscopy in patients undergoing screening or surveillance colonoscopy: a meta-analysis. Am J Gastroenterol 2012;107:363-70; quiz 371.

64. Jin XF, Chai TH, Shi JW, et al. Meta-analysis for evaluating the accuracy of endoscopy with narrow band imaging in detecting colorectal adenomas. J Gastroenterol Hepatol 2012;27:882-7.

65. Leung WK, Lo OSH, Liu KSH, et al. Detection of colorectal adenoma by narrow band imaging (HQ190) vs. high-definition white light colonoscopy: a randomized controlled trial. Am J Gastroenterol 2014;109:855-63.

66. Ogiso K, Yoshida N, Siah KTH, et al. New-generation narrow band imaging improves visibility of polyps: a colonoscopy video evaluation study. J Gastroenterol 2016;51:883-90.

67. Di Caro S, Fini L, Vega R, et al. Multicentre randomised controlled trial comparing standard and high resolution optical technologies in colorectal cancer screening. Frontline Gastroenterol 2019;10:244-52.

68. Parikh ND, Chaptini L, Njei B, et al. Diagnosis of sessile serrated adenomas/polyps with image-enhanced endoscopy: a systematic review and meta-analysis. Endoscopy 2016;48:731-9.

69. Backes Y, Moss A, Reitsma JB, et al. Narrow Band Imaging, Magnifying Chromoendoscopy, and Gross Morphological Features for the Optical Diagnosis of T1 Colorectal Cancer and Deep Submucosal Invasion: A Systematic Review and Meta-Analysis. Am J Gastroenterol 
2017;112:54-64.

70. Zhang QW, Teng LM, Zhang XT, et al. Narrow-band imaging in the diagnosis of deep submucosal colorectal cancers: a systematic review and meta-analysis. Endoscopy 2017;49:564-80.

71. Rees CJ, Rajasekhar PT, Wilson A, et al. Narrow band imaging optical diagnosis of small colorectal polyps in routine clinical practice: the Detect Inspect Characterise Resect and Discard 2 (DISCARD 2) study. Gut 2017;66:887-95.

72. Lee CK, Lee S-H, Hwangbo Y. Narrow-band imaging versus I-Scan for the real-time histological prediction of diminutive colonic polyps: a prospective comparative study by using the simple unified endoscopic classification. Gastrointest Endosc 2011;74:603-9.

73. Hoffman A, Loth L, Rey JW, et al. High definition plus colonoscopy combined with i-scan tone enhancement vs. high definition colonoscopy for colorectal neoplasia: A ran-domized trial. Dig Liver Dis 2014 Nov 1;46:991-6.

74. Kidambi TD, Terdiman JP, El-Nachef N, et al. Effect of I-scan Electronic Chromoendoscopy on Detection of Adenomas During Colonoscopy. Clin Gastroenterol Hepatol;17:701-8.e1.

75. Hoffman A, Sar F, Goetz M, Tresch A, et al. High definition colonoscopy combined with i-Scan is superior in the detection of colorectal neoplasias compared with standard video colonoscopy: a prospective randomized controlled trial. Endoscopy 2010;42:827-33.

76. Basford PJ, Longcroft-Wheaton G, Higgins B, et al. High-definition endoscopy with i-Scan for evaluation of small colon polyps: the HiSCOPE study. Gastrointest Endosc 2014;79:111-8.

77. Bowman EA, Pfau PR, Mitra A, et al. High Definition Colonoscopy Combined with i-SCAN Imaging Technology Is Superior in the Detection of Adenomas and Advanced Lesions Compared to High Definition Colonoscopy Alone. Diagn Ther Endosc 2015;2015:167406.

78. Bhandari P, Thayalasekaran S, Keisslich R, et al. Detection and characterization of colorectal polyps using highdefinition white light and i-Scan: Evidence-based consensus recommendations using a modified Delphi process. United European Gastroenterol J 2018;6:748-54.

79. Pohl J, Lotterer E, Balzer C, et al. Computed virtual chromoendoscopy versus standard colonoscopy with targeted indigocarmine chromoscopy: a randomised multicentre trial. Gut 2009;58:73-8.

80. Aminalai A, Rösch T, Aschenbeck J, et al. Live image processing does not increase adenoma detection rate during colonoscopy: a randomized comparison between FICE and conventional imaging (Berlin Colonoscopy Project 5, BECOP-5). Am J Gastroenterol 2010;105:2383-8.

81. Chung SJ, Kim D, Song JH, et al. Comparison of detection and miss rates of narrow band imaging, flexible spectral imaging chromoendoscopy and white light at screening colonoscopy: a randomised controlled back-toback study. Gut 2014;63:785-91.

82. Li L, Ou Y, Yue H, et al. Comparison of the detection of colorectal lesions in different endoscopic modalities: A network meta-analysis and systematic review. Exp Ther Med 2019;18:154-62.

83. Teixeira CR, Torresini RS, Canali C, et al. Endoscopic classification of the capillary-vessel pattern of colorectal lesions by spectral estimation technology and magnifying zoom imaging. Gastrointest Endosc 2009;69:750-6.

84. Longcroft-Wheaton GR, Higgins B, Bhandari P. Flexible spectral imaging color enhancement and indigo carmine in neoplasia diagnosis during colonoscopy: a large prospective UK series. Eur J Gastroenterol Hepatol 2011;23:903-11.

85. Laine L, Kaltenbach T, Barkun A, et al. SCENIC International Consensus Statement on Surveillance and Management of Dysplasia in Inflammatory Bowel Disease. Gastroenterology 2015;148:639-51.e28.

86. Kamiński MF, Hassan C, Bisschops R, et al. Advanced imaging for detection and differentiation of colorectal neoplasia: European Society of Gastrointestinal Endoscopy (ESGE) Guideline. Endoscopy 2014;46:435-49.

87. Danese S, Fiorino G, Angelucci E, et al. Narrow-band imaging endoscopy to assess mucosal angiogenesis in inflammatory bowel disease: A pilot study. World J Gastroenterol 2010;16:2396-400.

88. Iacucci M, Fort Gasia M, Hassan C, et al. Complete mucosal healing defined by endoscopic Mayo subscore still demonstrates abnormalities by novel high definition colonoscopy and refined histological gradings. Endoscopy 2015;47:726-34.

89. Ignjatovic A, East JE, Subramanian V, et al. Narrow band imaging for detection of dysplasia in colitis: a randomized controlled trial. Am J Gastroenterol 2012;107:885-90.

90. Bisschops R, Bessissow T, Joseph JA, et al. Chromoendoscopy versus narrow band imaging in UC: a prospective randomised controlled trial. Gut 2018;67:1087-94.

91. Kudo T, Matsumoto T, Esaki M, et al. Mucosal vascular pattern in ulcerative colitis: observations using narrow 
band imaging colonoscopy with special reference to histologic inflammation. Int J Colorectal Dis 2009;24:495.

92. Iacucci M, Kaplan G, Panaccione R, et al. A Randomized Trial Comparing High Definition Colonoscopy Alone With High Definition Dye Spraying and Electronic Virtual Chromo-endoscopy for Detection of Colonic Neoplastic Lesions During IBD Surveillance Colonoscopy. Am J Gastroenterol 2018;113:225-34.

93. Iacucci M, McQuaid K, Gui XS, et al. A multimodal (FACILE) classification for optical diagnosis of inflammatory bowel disease associated neoplasia. Endoscopy 2019;51:133-41.

94. Bisschops R, Bessissow T, Dekker E, et al. Pit pattern

doi: $10.21037 /$ tgh-19-373

Cite this article as: $\mathrm{Pal}$ P, Singh AP, Kanuri ND, Banerjee R. Electronic chromo-endoscopy: technical details and a clinical perspective. Transl Gastroenterol Hepatol 2022;7:6. analysis with high-definition chromoendoscopy and narrow-band imaging for optical diagnosis of dysplasia in patients with ulcerative colitis. Gastrointest Endosc 2017;86:1100-6.e1.

95. Iacucci M, Furfaro F, Matsumoto T, et al. Advanced endoscopic techniques in the assessment of inflammatory bowel disease: new technology, new era. Gut 2019;68:562-72.

96. Cassinotti A, Buffoli F, Fociani P, et al. Virtual Chromoendoscopy With FICE for the Classification of Polypoid and Nonpolypoid Raised Lesions in Ulcerative Colitis. J Clin Gastroenterol 2019;53:269-76. 